\title{
Giant Lipoma Infiltrating the Thigh with Vascular Distress: A Case Report
}

\section{Papa Amadou Ba*, Yves Girineza Ndabereye, Cheikh Coundoul, Abdoulaye Lindor Diop, Madior Diouf, René André Macodou Ndiaye and Coumba Diouf Niang}

Dakar Principal Hospital, Dakar, Senegal

*Corresponding Author: Papa Amadou Ba, Orthopedic Surgeon, Dakar Principal

Hospital, Dakar, Senegal.
Received: August 10, 2021

Published: August 26, 2021

(C) All rights are reserved by Papa Amadou

Ba., et al.

\begin{abstract}
Solitary lipoma is a frequent soft tissue tumor of multiple locations; indication for surgery when it is painful, unsightly and causes a functional gene. Benign mesenchymal tumor, it is said to be giant when its size is greater than $10 \mathrm{~cm}$ and/or weighs more than $1000 \mathrm{~g}$. It rarely degenerates into liposarcoma. We report the case of a giant infiltrating lipoma of the right thigh with vascular damage in a 62-year-old patient. The clinical picture was marked by a recurrent mass in the right thigh for about 16 years, painless, causing a significant functional gene. The preoperative radiological assessments (ultrasound and MRI) and the biopsy were in favor of the diagnosis and the indication for resection was retained.
\end{abstract}

Keywords: Giant Lipoma; Invasive Lipoma; Surgical Excision

\section{Abbreviation}

MRI: Magnetic Reasoning Imaging

\section{Introduction}

Lipoma is the most common benign soft tissue tumor, usually small, measuring less than five centimeters in $80 \%$ of cases [1]. It is, in general, subcutaneous and asymptomatic. When it is sub aponeurotic, it develops quietly, can reach very large proportions and be compressive [2]. It can, therefore, make think of malignant tumors such as liposarcoma and require further diagnostic means. We report the case of a compressive intramuscular lipoma of the thigh causing vascular distress.

\section{Case Report}

This was a 62-year-old patient with a history of excision of a mass in the right thigh 16 years ago, who presented a firm, painless swelling, measuring $22 \mathrm{~cm}$ in length and $14 \mathrm{~cm}$ in width at the posteromedial aspect of the right thigh (Figure 1). It is attached to the deep plane and causes an important functional gene. There were no local inflammatory signs, nor any superficial vascular net- work. The clinical examination showed slight edema of the lower limb which is due to a problem with venous return.

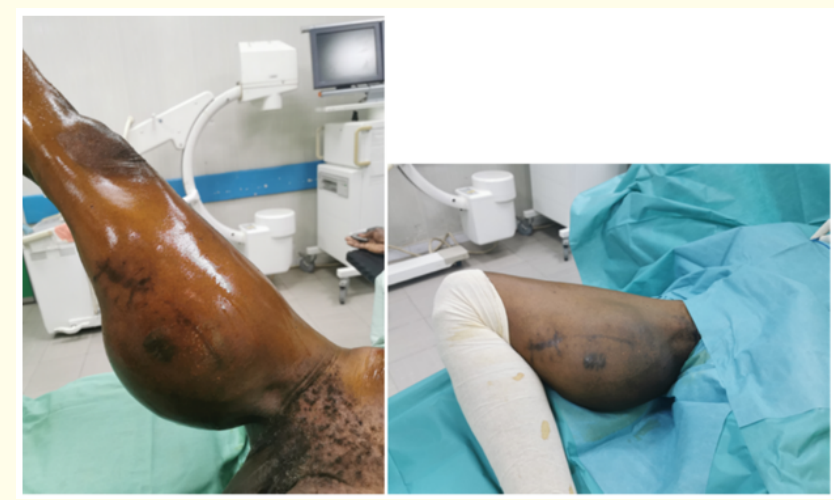

Figure 1: Posteromedial location of the lipoma in the thigh.

An echography of the mass was carried out and demonstrated an echogenic and heterogeneous tumor formation visible at the level of the postero-internal compartment of the adductors of the right thigh. 
MRI confirmed the well-limited fatty appearance with close contact with the superficial femoral artery without sheathing. Its dimensions were 25.09 X 10.47 X $11.58 \mathrm{~cm}$ (Figure 2).
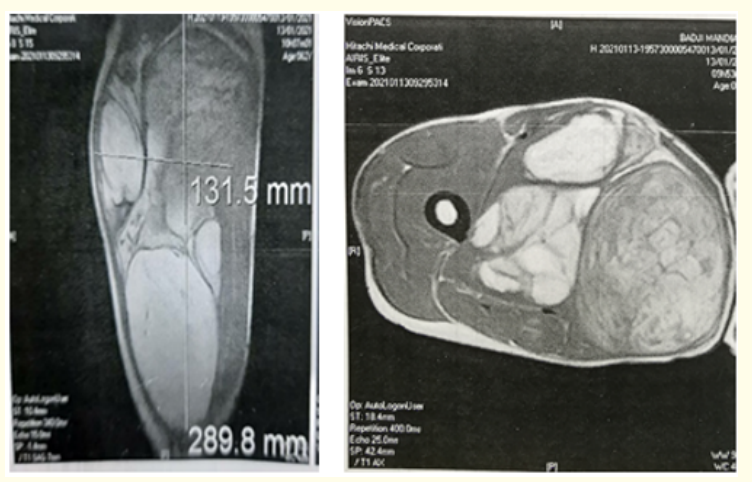

Figure 2: MRI image of the mass.

A biopsy of the mass was taken and the pathological analysis revealed a lesion consisting of sheets of mature adipocytes, devoid of cytonuclear atypia closely entangled with neighboring muscle tissue.

Surgical excision was performed with difficult dissection. Two ovoid sub-aponeurotic masses attached to the muscles of the medial and posterior compartments were highlighted, with a smooth surface with dimensions of 18 X $12 \mathrm{~cm}$ and 16 X $10 \mathrm{~cm}$, and a third dented in a potato bag of approximately $10 \mathrm{~cm}$ in diameter and two small masses about 3 to $4 \mathrm{~cm}$ in diameter (Figure 3). She weighed $1,9 \mathrm{~kg}$. The macroscopic appearance was in favor of a lipoma (Figure 4).
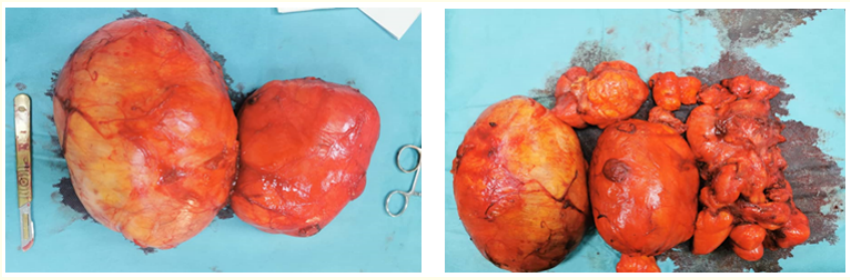

Figure 3: Fat mass after excision.

These masses presented close contact with the femoral vascular bundle with varicose dilation of the femoral vein confirmed by postoperative ecodoppler (Figure 5). They were also in contact with the sciatic nerve (Figure 6).

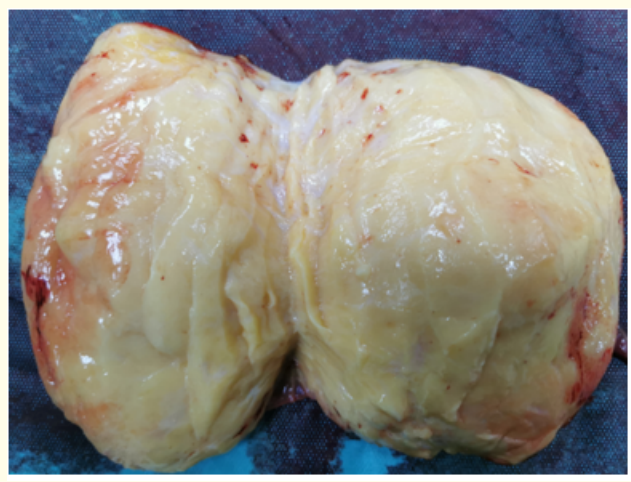

Figure 4: Macroscopic appearance in section.
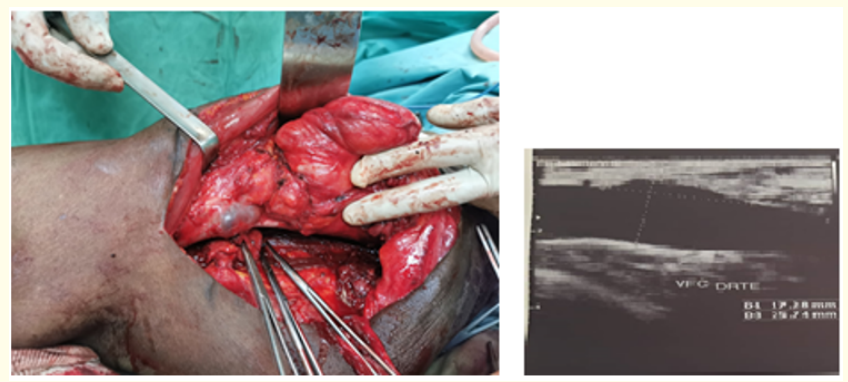

Figure 5: Varicose dilation of the femoral vein due to the mass.

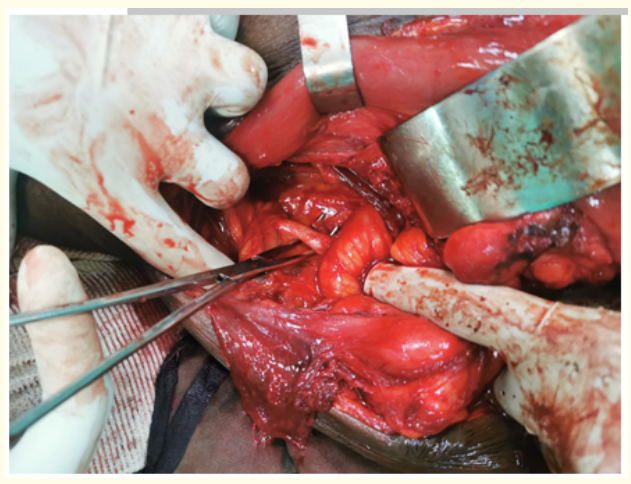

Figure 6: Close contact of the mass with the femoral nerve. 


\section{Discussion}

Lipoma is the most common tumor of all benign soft tissue tumors (16 to 50\%). It is said to be giant when its size exceeds $10 \mathrm{~cm}$ or its weight $1000 \mathrm{~g}[3,4]$ and is infiltrative when it is intramuscularly circumscribed, isolated, voluminous and readily symptomatic. Giant lipomas are large benign mesenchymal tumors formed by fatty lobules from mature adipose tissue, the exact etiology of which is not yet clear. Some authors speak of a sporadic hypothesis, or one that may fall within the framework of genetic diseases [5], others blame endocrine or metabolic disorders [6] or traumatic causes leading to the rupture of the fibrous partitions facilitating the passage and proliferation of 'adipose tissue and the constitution of lipoma [7]. In our patient, no cause was found: no notion of previous trauma, no metabolic or endocrine disorders could be observed; however, he underwent a previous resection of a lipomatous mass in his right thigh approximately 16 years ago.

Depending on the location, these tumors can be located in any part of the body where fatty tissue is located $[8,9]$. Localization in the limbs is relatively rare and comes after axial localization. In the limbs, lipomas are most often located in large muscles.

It occurs around the age of 50 with no gender predominance [10]. It often presents without clinical symptoms and therefore grows to a large size before detection [11]. It is in front of the monstrous character of the mass and the social embarrassment that the patient consults in the specialized medical sector after years of evolution [12]. Certain signs such as vascular and nerve compression can lead the patient to consult [2-13] as the case of our patient.

The deep localization of the mass requires carrying out additional etiological examinations. Ultrasound is useful in the volumetric assessment, but is not specific. The lipoma can be iso, hypo or hyperechoic. On the other hand, CT shows a mass of fat density around $80 \mathrm{Uh}$, not taking any contrast, which is characteristic [14]. MRI is the gold standard and allows the tumor to be located and its relationship to neighboring structures to be defined; it also makes it possible to specify the homogeneity orienting towards a benign character. In MRI, the fat is reflected by a hypersignal in T1 and a hypo signal in T2. Complementary examinations, correlated with the clinic, make it possible to differentiate between a benign lipoma and liposarcomas which are aggressive tumors. However, a number of criteria can predict the malignancy of a tumor: irregular boundaries, heterogeneity, large size, invasion of adjacent structures, presence of necrosis.
In case of hesitation, pathological examination remains essential. Macroscopically, when cut, the tumor appears as ordinary, yellow and uniform adipose tissue, traversed by muscle fibers in the intramuscular forms [15]. Microscopically, the tumor consists of mature, univacuolated fat cells, roughly uniform in size and without any cellular atypia [16].

The infiltrating-type intramuscular lipoma is a mass of mature adipocytes that infiltrate irregularly between muscle fibers and replace them in many places. Treatment of these tumors requires an initial biopsy to confirm the benign appearance of the tumor before final resection [17]. This was the case for our patient in whom a first biopsy was performed.

On the other hand, most surgeons, in front of a bundle of clinical and radiological arguments, perform an excisional biopsy in one step [18]. The surgical procedure includes a local excision of the tumor with wide resection removing the surrounding muscle tissue.

The local recurrence rate is zero for a well-circumscribed lipoma and it is $19 \%$ for an infiltrating lipoma according to Fletcher and Martin-Betes [16]. For Le Saout., et al. [19], degeneration into liposarcoma does not exist.

For some authors [20], the malignant transformation of lipoma to liposarcoma is relatively uncommon. A few reports suggest that large tumours ( $>10 \mathrm{~cm}$ in size) are more at risk of containing sarcoma cells, expecially in the presence of sudden rapid growth.

\section{Conclusion}

Lipoma is the most common tumor of all benign soft tissue tumors; said giant when its size $10 \mathrm{~cm}$ or $1000 \mathrm{~g}$ and is infiltrating when intramuscularly circumscribed, isolated, bulky and readily symptomatic. It can cause vascular and nerve compression leading the patient to consult. The deep localization of the mass requires carrying out additional etiological examinations. The treatment of choice for giant lipomas is surgical excision.

\section{Conflict of Interest}

Authors report no conflicts of interest related to this study.

\section{Bibliography}

1. Kransdorf MJ., et al. "Lipomatous tumors. Imaging of soft tissue tumors". W.B Saunders Company edit (1997): 57-101.

2. Garrido-Gómez J., et al. "Grande Intermittent claudication caused by a giant atypical lipoma of the thigh". Journal of Vascular Surgery 56.3 (2012): 808-811. 
3. Akinkunmi M., et al. "Giant fibrolipoma of the thigh in a Nigerian woman: a case report”. International Journal of Radiology 12.2 (2010): 1-8.

4. Dabloun S., et al. "lipome géant du dos a propos d'un cas". Annales de Dermatologie et de Vénéréologie - Journals 142.6 (2015): 353.

5. Pinski KS., et al. "Liposuction of lipomas”. Dermatologic Clinics 8.3 (1990): 483-492.

6. Turc-Carel C. "Breakpoints in benign lipoma may be at $12 \mathrm{q} 13$ or 12q14". Cancer Genetics and Cytogenetics 36.1 (1988): 131135.

7. Meggit BF., et al. "The battered buttock syndrome: fat fractures: a report on a group of traumatic lipomata". British Journal of Surgery 59.3 (1972): 165-169.

8. Zaroo MI., et al. "Giant lipoma: A case report". Journal of the Islamic Medical Association of North America 43.2 (2011): 7779.

9. Elbardouni A., et al. "Well-circumscribed deep-seated lipomas of the upper extremity. A report of 13 cases". Orthopaedics and Traumatology: Surgery and Research 97.2 (2011): 152-158.

10. Dionne G P., et al. "Infiltrating lipomas and angiolipomas revisited". Cancer 33.3 (1974): 732-738.

11. Kaeser MA., et al. "A case report of an intermuscular lipoma: presentation, pathophysiology, differential diagnostic". Journal of Chiropractic Medecine 9.3 (2010): 127-131.

12. 12. Sarr L., et al. "Giantinfiltratinglipoma: Two Cases Report". Journal Africain De Chirurgie 5.1 (2018): 58-62.

13. Chagou A., et al. "Lipome géant de la cuisse avec signes de souffrance nerveuse - à propos d'un cas". The Pan African Medical Journal 18 (2014): 296.

14. Elmrini A., et al. "Tuméfaction molle de l'épaule: un lipome intramusculaire". La Lettre du Rhumatologue (2007): 331.

15. Kindblom LG., et al. "Intermuscular and intramuscular lipomas and hibernomas”. Cancer 33.3 (1994): 754-762.

16. Fletcher CDM., et al. "Intramuscular and intermuscular lipoma: neglected diagnosis". Histopathology 12.3 (1988): 275-287.

17. Hunt JA., et al. "Giant infiltrating lipoma of the tigh causing sciatica”. ANZ Journal of Surgery 67.4 (1997): 225-226.
18. Josoa Rafaramino F., et al. "Deux cas de lipome géant au niveau de la cuisse”. Revista de Biología Tropical 1.2 (2007): 39-41.

19. Le Saout J., et al. "Lipomes profonds des membres. À propos de huit cas”. Annales de Chirurgie 38 (1984): 667-672.

20. Un Rydholm., et al. "Size, site and clinical incidence of lipoma. Factors in the differential diagnosis of lipoma and sarcoma". Acta Orthopaedica Scandinavica 54.6 (1983): 929-934.

\section{Volume 4 Issue 9 September 2021}

(C) All rights are reserved by Papa Amadou Ba., et al. 